\title{
Role of affective instability on suicidal risk in complex regional pain syndrome: a diary approach (preliminary report)
}

\author{
Saetbyeol Jeong, Jeongwi An, and Sungkun Cho \\ Department of Psychology, Chungnam National University, Daejeon, Korea
}

Received April 1, 2020

Revised October 10, 2020

Accepted October 11, 2020

Handling Editor: Jee Youn Moon

\section{Correspondence}

Sungkun Cho

Department of Psychology, Chungnam

National University, 99 Daehak-ro,

Yuseong-gu, Daejeon 34134, Korea

Tel: +82-42-821-6366

Fax: +82-42-823-9448

E-mail: sungkunc@cnu.ac.kr

Jeongwi An's current affiliation: Department of Psychology, West Virginia University, Morgantown, West Virginia, USA
Background: Many patients with complex regional pain syndrome (CRPS) have been known to be at risk of suicide, due to severe pain and its comorbid conditions. The risk of suicide may be associated with affective instability, which is an indicator of emotional dysregulation. Particularly, unstable shifts in negative emotions are difficult to cope with, which may result in individuals feeling uncontrollable, hopeless, and entrapped. This study aimed to examine the role of affective instability in the relationship between pain intensity and suicide risk (suicidal ideation and impulsivity) in patients with CRPS, by employing a daily diary.

Methods: Twenty-three patients registered at the CRPS Association in Korea were asked to complete a day-to-day routine for 15 days, followed by a diary composed of pain intensity, suicidal ideation, impulsivity, and positive and negative affects.

Results: Results showed that the interactions between negative affective instability and daily pain intensity were statistically significant on daily suicidal ideation (coefficient $=0.41, t(21)=2.56, P<0.050)$ and daily impulsiveness (coefficient $=1.20$, $t(19)=3.35, P<0.010)$. However, those between positive affective instability and daily pain intensity were not.

Conclusions: This study is the first attempt to investigate the role of affective instability on the relationship between daily pain intensity and daily suicide risk in patients with CRPS. Our findings suggest that health professionals pay considerable attention to the instability of negative affects when assessing and managing patients with CRPS at risk of suicide.

Key Words: Affect; Complex Regional Pain Syndromes; Emotions; Impulsive Behavior; Mood Disorders; Pain; Suicidal Ideation; Suicide.

\section{INTRODUCTION}

Complex regional pain syndrome (CRPS) is a chronic pain condition that may be caused by trauma, nerve injury, fracture, or surgery. Furthermore, it may have no specific cause [1]. CRPS has been known to be an extremely painful condition [1]. Consequently, many patients with CRPS are severely restricted in almost all areas of life $[2,3]$. These restrictions pose a substantial challenge to them in their lives, which may lead to emotional distress such as depression, anxiety, anger, frustration, and hopelessness [3-5]. Accordingly, patients with CRPS may have a higher risk of suicide [6]. An epidemiological study on CRPS has reported that $49.3 \%$ of patients with CRPS considered suicide and that the actual suicide attempt rate was $15.1 \%$ [7]. These rates are higher than those of the general population and other pain populations $[6,8]$.

The high risk of suicide may be associated with affective (c) This is an open-access article distributed under the terms of the Creative Commons Attribution Non-Commercial License (http://creativecommons.org/licenses/by-nc/4.0/), which permits unrestricted non-commercial use, distribution, and reproduction in any medium, provided the original work is properly cited.

(C) The Korean Pain Society, 2021
Author contributions: Saetbyeol Jeong: Writing/manuscript preparation; Jeongwi An: Writing/manuscript preparation; Sungkun Cho: Supervision. 
instability, which is an indicator of emotional dysregulation [9]. Affective instability is defined as marked, frequent, and abrupt shifts between different emotions (e.g., neutral and anger), usually involving negative emotions [10]. Specifically, such unstable shifts in negative emotions are difficult to cope with, which may result in individuals feeling uncontrollable, hopeless, and entrapped $[11,12]$. Consequently, suicidogenic cognitive structures may develop, in part, as a response to escape such negative emotions [13]. Repeated fluctuations in negative emotions can make these structures more elaborated, entrenched, and sensitive [13]. Furthermore, individuals who are emotionally unstable often lose their control of and/or exaggerate emotional responses to internal or external events. They may tend to act impulsively accordingly, possibly increasing the risk for suicide behaviors [14].

Patients with CRPS often experience flare-ups [15]. Such flare-ups are difficult to cope with and manage [1], and accordingly, the patients' emotions are likely to fluctuate. Repeated fluctuations in negative emotions can develop elaborated, entrenched, and sensitive suicidogenic cognitive structures, thereby increasing the risk for suicide behaviors [14]. A recent diary study [16] may elucidate this relationship although no studies have yet investigated the role of affective instability on suicide risk in patients with chronic pain including CRPS. This study demonstrated that affective instability moderated the relationship between daily pain intensity and pain outcomes (i.e., daily disability, cognitive complaints) in patients with chronic pain. Specifically, the greater the daily pain intensity, the greater the daily disability and cognitive complaints, but only when negative affect instability was high. However, the relationship between daily pain intensity and daily pain outcomes was not moderated by positive affect instability. Given these circumstances, the dynamics of pain intensity and affective instability (especially negative affect instability) may heighten suicide risk in patients with CRPS.

Affective instability is a state of variable mood shifts [17], which require measurement to determine the changes over time while the range of mood changes is considered. Thus, the daily measurement of affective instability may ensure the ecological validity of the results [18]. We hypothesized that affective instability moderates the relationship between daily pain intensity and daily suicide risk (i.e., suicidal ideation, impulsivity) in patients with CRPS, controlling for some covariates. Specifically, the higher the level of affective instability, the greater the impact of daily pain intensity on suicide risk that is, suicidal ideation and impulsivity, in patients with CRPS. This study aimed to examine the role of affective instability in the relationship between pain intensity and suicide risk in pa- tients with CRPS by employing a daily diary.

\section{MATERIALS AND METHODS}

\section{Participants}

The participants included 23 patients who registered at the CRPS Association in Korea. The inclusion criteria for this study were 1) diagnosed with CRPS, 2) aged over 19 years old, 3) fluent in Korean, and 4) able to answer an online questionnaire. The participants were recruited by utilizing the bulletin board on the CRPS Association homepage. Although the data were collected from 25 patients, two patients were excluded for not completing all the items in the baseline questionnaire. Therefore, the data of 23 patients were used for the analysis. All data were obtained appropriately after participants had provided informed consent. The characteristics of the sample are presented in Table 1. This study was approved by the Institutional Review Board of Chungnam National University (201702-SB-015-01).

\section{Measures}

1) Baseline questionnaire

(1) Pain intensity

A numerical rating scale (NRS) was used to measure pain intensity. The NRS comprises four items that assess pres-

Table 1. Characteristics of the study sample

\begin{tabular}{lc}
\hline \multicolumn{1}{c}{ Variable } & Value \\
\hline Sex & \\
Male & 78.3 \\
Age (yr) & $40.0 \pm 8.7$ \\
Marital status & \\
$\quad$ Married & 52.2 \\
Education level & \\
$\quad$ High school & 95.6 \\
Most significant pain site(s) & \\
$\quad$ Arm & 17.4 \\
Leg & 39.1 \\
$\quad$ Arm and leg & 21.7 \\
$\quad$ Others & \\
Pain duration (mo) & 21.8 \\
Prescribed pain-related medication & $60.0(11-212)$ \\
Pain-related finance support & 95.7 \\
Pain-related court action & 73.9 \\
\hline
\end{tabular}

Values are presented as percentage, mean \pm standard deviation, or median (range).

${ }^{a}$ Others include head, back, and foot. 
ent and usual, lowest, and highest pain during the previous week. The items are measured on an 11-point Likert scale, ranging from 0 (no pain) to 10 (greatest pain imaginable). The total scores range from 0 to 10 , with a higher score indicating a higher intensity of pain.

\section{(2) Depression}

The Korean version of the Hospital Anxiety-Depression Scale (HADS) [19] was employed to measure anxiety and depression. This scale consists of 14 items and two subscales for anxiety and depression. Each item is measured on a 4-point Likert scale. The total scores range from 0 to 21, with a higher score indicating a higher level of anxiety or depression. However, only the depression scale was used in this study. The internal consistency for the HADSDepression was $\alpha=0.82$ [20] and for the Korean version of HADS-Depression in this study, $\alpha=0.94$.

\section{(3) Suicidal ideation}

The Korean version of the Scale for Suicidal Ideation (SSI) [21] was employed to measure suicidal ideation. This scale consists of 19 items. Each item is measured on a 3-point Likert scale. The total scores range from 0 to 38 , with a higher score indicating a higher level of suicidal ideation. The internal consistency for the SSI was $\alpha=0.89$ [22] and $\alpha$ $=0.92$ for the Korean version of the SSI in this study.

\section{(4) Impulsivity}

The Korean version of the Barratt Impulsiveness Scale-11 (BIS-11) [23] was used to measure impulsivity. This scale comprises 30 items. Each item is measured on a 4-point Likert scale, ranging from 1 (not at all) to 4 (always). The total scores ranges from 30 to 120 , with a higher score indicating a higher level of impulsivity. The internal consistency for the BIS-11 was $\alpha=0.79$ to 0.83 [24], and $\alpha=0.93$ for the Korean version of the BIS-11 in this study.

\section{2) Pain diary (Appendix)}

(1) Daily pain intensity

The NRS for pain intensity used in the baseline questionnaire was used to measure daily pain intensity.

(2) Daily suicidal ideation

NRS was used to measure suicidal ideation during the day. This scale comprises one item, which is measured on an 11-point Likert scale, ranging from 0 (not at all) to 10 (very much). A higher score indicates a higher level of suicidal ideation.

\section{(3) Daily mood}

The Daily Mood Scale (DMS) [25] was used to measure mood during the day. This scale consists of nine items and two subscales; the nine items included four items to assess a positive mood and five to assess a negative mood. Although all of the original items of the DMS were retained in this study, its instructions were modified to reflect the daily aspect of the study. Each item is measured on a 6 -point Likert scale, ranging from 0 (not at all) to 5 (always). The total scores range from 0 to 20 and 0 to 25 for a positive and negative mood, respectively. A higher score indicates a higher level of the corresponding mood. The internal consistency for the DMS was $\alpha=0.89$ for positive mood and $\alpha=0.84$ for negative mood [25] and $\alpha=0.87$ for positive mood and $\alpha=0.89$ for negative mood for the Korean version of the DMS in this study.

\section{(4) Daily impulsivity}

The Korean version of the UPPS-P Impulsive Behavior Scale (UPPS-P) [26] was employed to measure impulsivity. This scale consists of 59 items and five subscales: Negative urgency, positive urgency, lack of premeditation, lack of perseverance, and sensation seeking. Each item is measured on a 4-point Likert scale, ranging from 1 (strongly agree) to 4 (strongly disagree). In this study, we used 12 items of negative urgency as a subscale most relevant to suicide. To reflect the daily aspect of the study, instructions were modified. The total scores range from 12 to 48 , with a higher score indicating a higher level of impulsivity. The internal consistency for the UPPS-P Negative Urgency subscale was $\alpha=0.86$ [27] and $\alpha=0.91$ for the Korean version of the UPPS-P Negative Urgency subscale in this study.

\section{Procedure}

The participants were informed about the purposes and procedures of this study telephonically. On the first day of the study, they completed a demographic questionnaire, and a baseline questionnaire that assessed pain intensity, depression, suicidal ideation, and impulsivity through Google forms on the internet. Subsequently, the participants completed an internet pain diary for 15 consecutive days. The researcher used notification messages to encourage them to complete their pain diary every day at 20:00. The researcher used a notification message to encourage them to complete their pain diary the next day 
before 11:00 if they had not done so on the previous day. The observations where the pain diary was not completed in time was $13.6 \%$ ( 47 out of 345 observations [23 participants $\times 15$ days]). It took the participants approximately 15-20 minutes to complete the demographic and baseline questionnaires, and 5-10 minutes every day to complete the pain diary for the next 15 days. If they did not complete their pain diary for more than two of the 15 days, they were no longer allowed to participate in the study and their data were excluded from the analysis. When all the procedures had been completed, the participants were debriefed telephonically, and each participant was paid 50,000 won (equivalent to about 40 US dollars) for their participation.

\section{Data analysis}

Affective instability involves emotional variability and temporal dependency; thus, this study used the mean square successive difference (MSSD) to measure it [28]. The MSSD measures the difference between two consecutive observations and calculates them by means, reflecting the average magnitude and frequency of emotional changes [18]. In this study, positive and negative affect instability were calculated separately; the higher the MSSD value, the higher the affective instability. The formula for calculating affective instability follows. In the following expression, $N$ is the total number of measurements, $t$ is the order of measurements, and $X_{t}$ is the consecutive observations ( $X$ measured in time period $t$ ).

$$
\operatorname{MSSD}=\frac{\sum_{t=2}^{N}\left(X_{t}-X_{t-1}\right)^{2}}{N-1}
$$

The collected data were analyzed using SPSS 22.0 (IBM Co., Armonk, NY) and the Hierarchical Linear Modeling (HLM) software package (Scientific Software International, Skokie, IL, https://ssicentral.com/). A correlation analysis was conducted to examine the relationship between affective instability and baseline variables. HLM (also known as multilevel modeling) is a model that analyzes the data in which lower-level variables (e.g., individuals) are nested within higher-level variables (e.g., contextual/ aggregate variables). HLM allows a cross-level interaction, and thus can determine that a higher-level variable (i.e., affective instability) is moderating the relationship between a lower-level variable and an outcome variable (i.e., daily pain intensity and daily suicide risk) [29]. The data collected by the pain diary had multilevel characteristics that were measured daily (level 1) nested in the individual (level 2). Level 1 included the repeated measures (i.e., positive and negative affects, pain intensity, suicidal ideation, and impulsivity), and level 2 included the indi-

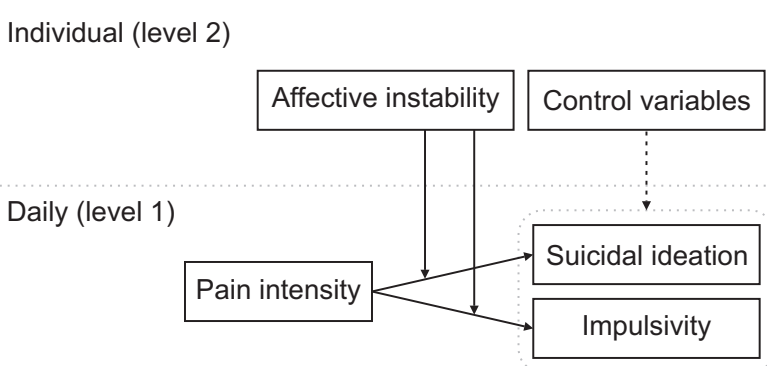

Fig. 1. The data collected by the pain diary had multilevel characteristics that were measured daily (level 1) nested in the individual (level 2). Level 1 included the repeated measures (i.e., positive and negative affects, pain intensity, suicidal ideation, and impulsivity), and level 2 included the individual measures (i.e., sex, age, pain duration, pain-related finance support, pain-related court action, pain intensity, depression, suicidal ideation, and impulsivity).

vidual measures (i.e., sex, age, pain duration, pain-related financial support, pain-related court action, pain intensity, depression, suicidal ideation, and impulsivity) (Fig. 1). The statistical procedures employed by Rost et al. [16] were primarily followed. Specifically, the full maximum likelihood estimation was used to estimate each coefficient in the models [30]. Furthermore, the variables measured with the baseline questionnaire, namely, sex, age, pain duration, pain-related financial support, pain-related court action, pain intensity, depression, suicidal ideation, and impulsivity as well as those of the pain diary, that is, positive and negative affects were used as control variables. In addition, if the main effect of the control variable(s) was not statistically significant, then it was excluded from the final model [31].

\section{RESULTS}

\section{Preliminary correlation analyses}

Pearson correlations between level 1 and level 2 variables were calculated. The results demonstrated that, in general, the correlations between level 1 variables were significant. Specifically, daily pain intensity was positively correlated with daily suicidal ideation, but not daily impulsivity. The results indicated that patients with CRPS who showed greater daily pain intensity had more daily suicidal ideation. Also, for level 2 variables, negative affect instability was positively correlated with depression, and that positive affect instability was positively related to depression and negatively related to pain intensity and impulsivity. Furthermore, the results indicated that patients with CRPS who showed higher negative affect instability were more 


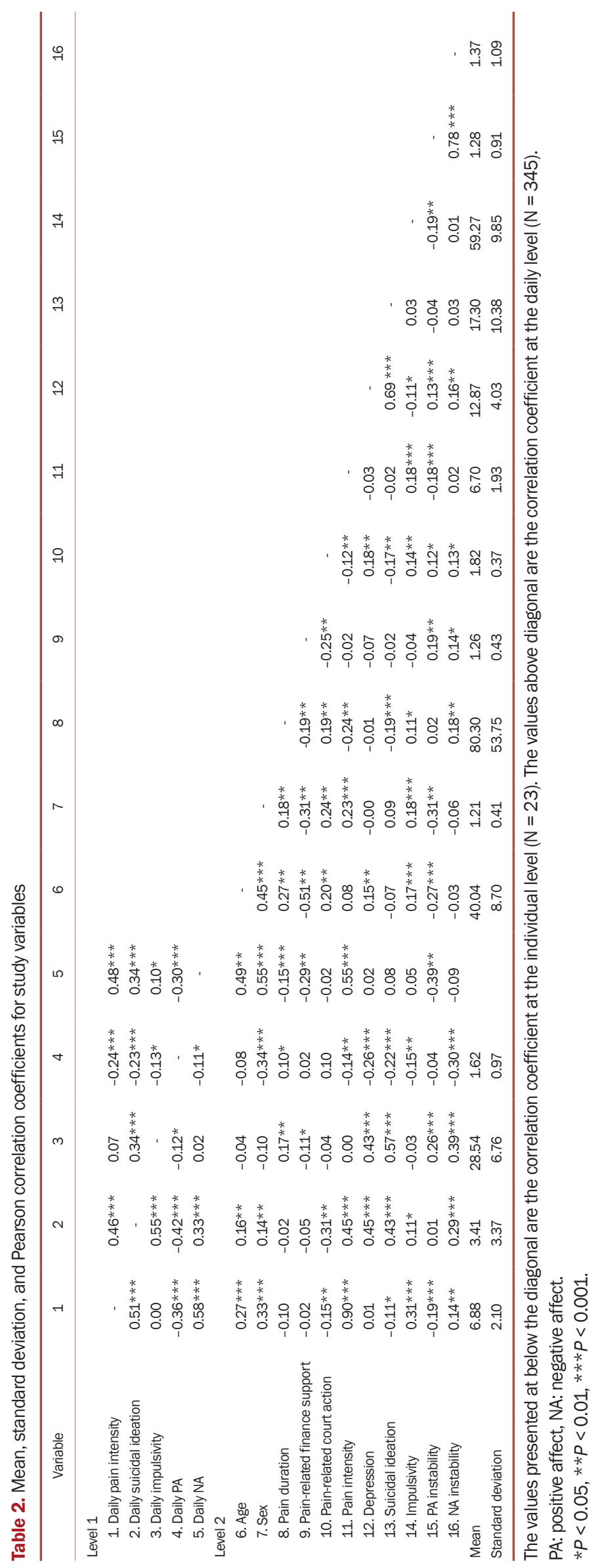


Table 3. Hierarchical linear models (final): effects of daily pain intensity and negative affect instability on daily suicidal risk

\begin{tabular}{lccc}
\multicolumn{1}{c}{ Dependent variable } & Coefficient & Standard error & T \\
\hline Intercept & 3.43 & 0.52 & $6.55 * * *$ \\
Negative affect instability $\rightarrow$ Daily suicidal ideation & 0.42 & 0.48 & 0.88 \\
Baseline pain intensity $\rightarrow$ Daily suicidal ideation & 0.75 & 0.26 & $2.82 *$ \\
[Daily pain intensity $\times$ Negative affect instability] $\rightarrow$ Daily suicidal ideation & 0.41 & 0.15 & $2.56 *$ \\
Intercept & 28.54 & 0.71 & 0.66 \\
Negative affect instability $\rightarrow$ Daily impulsivity & 1.39 & 0.01 & $2.09 *$ \\
Pain duration $\rightarrow$ Daily impulsivity & 0.02 & 0.07 & $1.27 *$ \\
Baseline suicidal ideation $\rightarrow$ Daily impulsivity & 0.23 & 0.37 & $3.39 * *$ \\
[Daily pain intensity $\times$ Negative affect instability] $\rightarrow$ Daily impulsivity & 1.20 & $3.35 * *$ \\
\hline
\end{tabular}

Level 1 predictor: daily pain intensity, daily suicidal ideation, daily impulsivity, Level 2 predictor: pain duration, baseline pain intensity, baseline suicidal ideation, negative affect instability.

$* P<0.05, * * P<0.01, * * * P<0.001$.

depressed, whereas those who showed higher positive affect instability were more depressed, had lesser pain, and were less impulsive. Table 2 presents the mean \pm standard deviation (SD) and Pearson correlations between level 1 and level 2 variables.

\section{Hierarchical linear models}

\section{1) Daily suicidal ideation}

The intraclass correlation coefficient (ICC) was calculated for the null model to estimate the proportion of variance explained by differences within and between individuals. The ICC of suicidal ideation was 0.29 , with $29 \%$ of the variance residing between individuals and $71 \%$ residing within individuals. These results indicated that variance within individuals is greater than variance between individuals, and that this research model can be analyzed at multiple levels. A null model with no predictors was examined to investigate the effect of variance within (level 1) and between (level 2) predictors on suicidal ideation, and then the daily pain intensity was added as the level 1 predictor. Subsequently, negative affect instability was added as the level 2 predictor, and baseline questionnaire variables as control variables. The final model included the interaction between daily pain intensity (level 1) and negative affect instability (level 2), with the control variable (i.e., baseline pain intensity) being significant in the previous model. Thereafter, the model fit of the current model was compared with that of the previous model by using the values to determine whether the current model is more suitable than the previous one. The value of the model with daily pain intensity as the level 1 predictor was 728.94 , while the model with negative instability as the level 2 predictor was 451.71 , and the final model was 422.13 , indicating that the final model was statistically more suitable than the previous models. In the final model, negative affect instability moderated the relationship between daily pain intensity and daily suicidal ideation (coefficient $=0.41, t(21)=2.56$, $P<0.050$ ) (Table 3). Post-hoc analyses indicated that the greater the daily pain intensity, the more daily suicidal ideation occurred; however, this was only when negative affect instability was high.

Next, for positive affect instability, the final model included the interaction between daily pain intensity (level 1) and positive affect instability (level 2), with the control variable (i.e., baseline pain intensity) being significant in the previous model. The value of the model with positive instability as the level 2 predictor was 527.13 , and the final model was 422.13 , indicating that the final model was statistically more suitable than the previous models. In the final model, positive affect instability did not moderate the relationship between daily pain intensity and daily suicidal ideation (coefficient $=0.27, t(21)=1.20, P=0.250$ ) (Table 4).

\section{2) Daily impulsivity}

The ICC of impulsivity was 0.41 , with $41 \%$ of the variance residing between individuals and $59 \%$ residing within individuals. The same procedure, described above, was applied. The final model included the interaction between daily pain intensity (level 1) and negative affect instability (level 2), with the control variables (i.e., pain duration and baseline suicidal ideation) being significant in the previous model. The value of the model with daily pain intensity as the level 1 predictor was 257.24 , the model with negative instability as the level 2 predictor was 223.55 , and the final model was 197.19, indicating that the final model was statistically more suitable than the previous models. In the final model, negative affect instability moderated the relationship between daily pain intensity and daily impulsivity (coefficient $=1.20, t(19)=3.35, P<0.010$ ) (Table 3). Post-hoc analyses revealed that the greater the daily 
Table 4. Hierarchical linear models (final): effects of daily pain intensity and positive affect instability on daily suicidal risk

\begin{tabular}{lccc}
\multicolumn{1}{c}{ Dependent variable } & Coefficient & Standard error & T \\
\hline Intercept & 3.43 & 0.53 & $0.42 * * *$ \\
Positive affect instability $\rightarrow$ Daily suicidal ideation & 0.05 & 0.60 & 0.08 \\
Baseline pain intensity $\rightarrow$ Daily suicidal ideation & 0.73 & 0.27 & $2.69 *$ \\
[Daily pain intensity $\times$ Positive affect instability] $\rightarrow$ Daily suicidal ideation & 0.27 & 0.21 & 1.20 \\
Intercept & 28.54 & 0.73 & $38.96 * * *$ \\
Positive affect instability $\rightarrow$ Daily impulsivity & 1.38 & 0.80 & 1.73 \\
Pain duration $\rightarrow$ Daily impulsivity & 0.02 & 0.01 & $1.36 *$ \\
Baseline suicidal ideation $\rightarrow$ Daily impulsivity & 0.23 & 0.07 & $3.34 * *$ \\
[Daily pain intensity $\times$ Positive affect instability] $\rightarrow$ Daily impulsivity & 1.07 & 0.51 & 2.06 \\
\hline
\end{tabular}

Level 1 predictor: daily pain intensity, daily suicidal ideation, daily impulsivity, Level 2 predictor: pain duration, baseline pain intensity, baseline suicidal ideation, positive affect instability.

$* P<0.05, * * P<0.01, * * * P<0.001$

pain intensity, the more daily impulsivity occurred; however, this only occurred when negative affect instability was high (Table 3).

Next, for positive affect instability, the final model included the interaction between daily pain intensity (level 1) and positive affect instability (level 2), with the control variable (i.e., pain duration and baseline suicidal ideation) being significant in the previous model. The value of the model with positive instability as the level 2 predictor was 245.38, and the final model was 158.11, indicating that the final model was statistically more suitable than the previous models. In the final model, positive affect instability did not moderate the relationship between daily pain intensity and daily impulsivity (coefficient $=1.07, t(21)=2.06$, $P=0.107$ ) (Table 4).

\section{DISCUSSION}

Negative affect instability appears to play an important role in the high risk of suicide, particularly in patients with CRPS who experience immense pain. In accordance with previous studies, this suggests that negative affect instability is closely related to pain $[11,16]$. CRPS often involves extreme, persistent, intractable pain [32], which may result in persistent negative affects. In particular, occasional flare-ups are uncontrollable and/or unpredictable, possibly fueling negative emotional hyperreactivity. Affective instability is a facet of emotional dysregulation. The latter refers to "the inability to flexibly respond to and manage emotions" [33]. Many patients with CRPS face numerous challenges because of pain and its consequences $[32,34]$. Repeated exposure to such challenges over a long period of time may increasingly stimulate the development of catastrophic thoughts, which may interfere with patients' ability to regulate negative emotions [35]. Difficulties encountered in the regulation of negative emotions are asso- ciated with the development and maintenance of suicidal ideations and behaviors [35]. Specifically, repeated failure in emotional regulation may result in patients developing more elaborate suicidogenic cognitive structures as means of escaping from their pain and emotional distress. If left untreated, this downward spiral of pain sensations, catastrophic thoughts, and dysregulated negative emotions are more likely to increase risk for suicidal ideations and behaviors [16].

In this study, the role of negative affect instability implies that the impact of emotional experience on patients with CRPS may be more extensive. Previous studies have argued that patients who are struggling with emotional dysregulation also have problems coping with pain [16]. Hamilton et al. [36] found that emotional regulation moderates the relationship between pain and negative emotion. They argued that for individuals vulnerable to emotional dysregulation, the impact of pain on suffering, such as negative emotions, is greater in comparison to those with more emotional regulation skills. Severe pain in conjunction with negative affect instability may increase negative emotions. Furthermore, patients who are vulnerable to negative affect instability tend to be more negative about their situations and emotional experiences by catastrophizing the results of their own experiences [37]. When the immense difficulties of CRPS are considered, one may assume that risk of suicide increases by responding more negatively to one's own situation such as unemployment and family difficulties and/or emotional experiences such as depression and anxiety.

However, the relationship between daily pain intensity and daily suicide risk was not moderated by the instability of positive affect. This result concurs with a previous study that showed that the relationship between pain intensity and pain outcomes was not moderated by positive affect instability [16]. This is possibly due to the nature of positive affect experiences of the sample of this study. Al- 
though the mean and variability of negative and positive affect instability was similar, those of the positive affects (1.62 \pm 0.97$)$ were lower than those of the negative affects $(2.73 \pm 2.09)$. This suggests that the participants in this study experienced invariably low positive emotions. Gross [38] argued that when recognizing a certain emotion, the preceding event or situation affects emotion recognition. Considering that CRPS often involves extreme, persistent, intractable pain, and leads to impairment in daily living activities [18,32], the participants may have invariably recognized low positive emotions.

In this study, it is noteworthy that to measure affective instability, the range of emotional changes over time was considered. In order to enhance an understanding of psychological disorders, there has been a growing interest in a third emotional state in recent years [39]. The third emotional state refers to affective instability [10]. Affective instability has been found to be linked to various areas of psychopathology including depression [40], anxiety [41], impulsive and aggressive behavior [42], as well as suicidal ideation and suicide attempts [17]. Furthermore, the results of this study showed that affective instability can enhance an understanding of suicidal ideation and impulsive experiences of patients with CRPS in their daily lives. Considering its influence, it is necessary to treat emotional instability as universal psychopathology that can be found across various pathologies rather than as sub-specific features of specific disorders [39,43].

This study has clinical implications for the understanding of patients with CRPS at risk of suicide. In programs for management of those at suicide risk, the primary target needs to be a reduction in the instability of negative affects. This may be achieved by emotional regulation strategies $[16,44]$. Cognitive reappraisal is one of the most widely used adaptive strategies, particularly for intense or persistent negative emotions [35]. CRPS often does not respond well to treatments [34]. Thus, catastrophic thoughts, such as believing the condition will never get better, may increasingly develop over time. Such negative appraisals are likely to lead to suicidal ideation or suicide attempts as a final resort to escape pain and emotional distress [35]. Thus, health professionals should consider assisting patients to interpret pain sensations, and situations or events, in more adaptive ways including cognitive reappraisals to decrease their negative emotions.

This study has several limitations. First, the sample size was relatively small $(\mathrm{N}=23)$ and the majority of the sample were male (78.26\%). CRPS-I occurs more frequently in female than male [35]. Also, participants were patients registered at the CRPS Association in Korea, but we did not attempt to obtain further information from them re- garding their diagnosis. Given that CRPS is difficult to diagnose accurately and its symptoms vary from person to person, it is difficult to generalize the results of the study to all patients with CRPS. Second, we collected data once a day to reduce the burden on patients with CRPS complaining of severe pain. Although a day was a unit of analysis, the number of observations may not be enough to reflect affective instability. Furthermore, because the participants completed the pain diary at night, recall biases may have affected the collected data. Therefore, future studies need to employ a longer period of data collection, such as 30 days, and/or collect data multiple times a day. Third, patients with CRPS often have a history of psychological comorbidities such as depression, anxiety, and posttraumatic stress disorder [45]. Since affective instability is a key component in many psychological disorders [39], the results of this study may vary depending on the presence or absence of psychological comorbidities. However, this study did not control for them. Fourth, in the absence of a control group, it remains unclear whether negative affect instability moderates the relationship between daily pain intensity and daily suicide risk. In sum, this small, biased sample may systematically over- or underestimate the corresponding parameter, and thus the results of this study should be replicated with more representative samples.

In conclusion, this study is the first attempt to investigate the role of affective instability on the relationship between daily pain intensity and daily suicide risk in patients with CRPS. This study demonstrated the relative importance of the instability of negative affects on the relationship between daily pain intensity and daily suicide risk. Our findings suggest that health professionals should pay more attention to the instability of negative affects when assessing and managing patients with CRPS at risk of suicide. Given that studies on the dynamics of pain intensity and affective instability for suicide risk in patients with chronic pain including CRPS are still in their infancy, future endeavors should attempt to replicate our findings and make them more relevant for clinical practice.

\section{CONFLICT OF INTEREST}

No potential conflict of interest relevant to this article was reported.

\section{FUNDING}

No funding to declare. 


\section{ORCID}

Saetbyeol Jeong, https://orcid.org/0000-0002-8152-0934

Jeongwi An, https://orcid.org/0000-0003-0074-3640

Sungkun Cho, https://orcid.org/0000-0003-3085-0658

\section{REFERENCES}

1. de Mos M, de Bruijn AG, Huygen FJ, Dieleman JP, Stricker $\mathrm{BH}$, Sturkenboom MC. The incidence of complex regional pain syndrome: a population-based study. Pain 2007; 129: 12-20.

2. Albazaz R, Wong YT, Homer-Vanniasinkam S. Complex regional pain syndrome: a review. Ann Vasc Surg 2008; 22: 297306.

3. Ciccone DS, Bandilla EB, Wu W. Psychological dysfunction in patients with reflex sympathetic dystrophy. Pain 1997; 71: 323-33.

4. Bruehl S, Husfeldt B, Lubenow TR, Nath H, Ivankovich AD. Psychological differences between reflex sympathetic dystrophy and non-RSD chronic pain patients. Pain 1996; 67: 107-14.

5. Hardy MA, Merritt WH. Psychological evaluation and pain assessment in patients with reflex sympathetic dystrophy. J Hand Ther 1988; 1: 155-64.

6. Edwards RR, Smith MT, Kudel I, Haythornthwaite J. Painrelated catastrophizing as a risk factor for suicidal ideation in chronic pain. Pain 2006; 126: 272-9.

7. Sharma A, Agarwal S, Broatch J, Raja SN. A web-based crosssectional epidemiological survey of complex regional pain syndrome. Reg Anesth Pain Med 2009; 34: 110-5.

8. Kamen C, Pryor LR, Gaughan ET, Miller JD. Affective lability: separable from neuroticism and the other big four? Psychiatry Res 2010; 176: 202-7.

9. American Psychiatric Association. Diagnostic and statistical manual of mental disorders. 4th ed. Washington, D.C., American Psychiatric Association. 2000.

10. McConville C, Cooper C. Personality correlates of variable moods. Pers Individ Dif 1998; 26: 65-78.

11. Taylor VA, Ellenbogen MA, Washburn D, Joober R. The effects of glucocorticoids on the inhibition of emotional information: a dose-response study. Biol Psychol 2011; 86: 17-25.

12. Taylor VA, Grant J, Daneault V, Scavone G, Breton E, RoffeVidal S, et al. Impact of mindfulness on the neural responses to emotional pictures in experienced and beginner meditators. Neuroimage 2011; 57: 1524-33.

13. Palmier-Claus JE, Taylor PJ, Varese F, Pratt D. Does unstable mood increase risk of suicide? Theory, research and practice. J Affect Disord 2012; 143: 5-15.

14. Merskey H, Bogduk N; Task Force on Taxonomy of the International Association for the Study of Pain. Classification of chronic pain: descriptions of chronic pain syndromes and definitions of pain terms. Seattle: IASP press 1994.

15. Astifidis RP. Pain-related syndromes: complex regional pain syndrome and fibromyalgia. In: Fundamentals of hand therapy: clinical reasoning and treatment guidelines for common diagnoses of the upper extremity. Edited by Cooper C. St. Louis, Mosby Elsevier. 2007, pp 376-88.

16. Rost S, Van Ryckeghem DM, Koval P, Sütterlin S, Vögele C, Crombez G. Affective instability in patients with chronic pain: a diary approach. Pain 2016; 157: 1783-90.

17. Links PS, Eynan R, Heisel MJ, Nisenbaum R. Elements of affective instability associated with suicidal behaviour in patients with borderline personality disorder. Can J Psychiatry 2008; 53: 112-6.

18. Trull TJ, Solhan MB, Tragesser SL, Jahng S, Wood PK, Piasecki TM, et al. Affective instability: measuring a core feature of borderline personality disorder with ecological momentary assessment. J Abnorm Psychol 2008; 117: 647-61.

19. Oh SM, Min KJ, Park DB. A study on the standardization of the Hospital Anxiety and Depression Scale for Koreans: a comparison of normal, depressed and anxious groups. J Korean Neuropsychiatr Assoc 1999; 38: 289-96.

20. Bjelland I, Dahl AA, Haug TT, Neckelmann D. The validity of the Hospital Anxiety and Depression Scale. An updated literature review. J Psychosom Res 2002; 52: 69-77.

21. Shin MS, Park KB, Oh KJ, Kim ZS. A study of suicidal ideation among high school students: the structural relation among depression, hopelessness, and suicidal ideation. Korean J Clin Psychol 1990; 9: 1-19.

22. Beck AT, Kovacs M, Weissman A. Assessment of suicidal intention: the Scale for Suicide Ideation. J Consult Clin Psychol 1979; 47: 343-52.

23. Heo SY, Oh JY, Kim JH. The Korean version of the Barratt Impulsiveness Scale, 11th version: its reliability and validity. Korean J Psychol Gen 2012; 31: 769-82.

24. Patton JH, Stanford MS, Barratt ES. Factor structure of the Barratt impulsiveness scale. J Clin Psychol 1995; 51: 768-74.

25. Diener E, Emmons RA. The independence of positive and negative affect. J Pers Soc Psychol 1984; 47: 1105-17.

26. Lim SY, Lee YH. A Korean validation of the UPPS-P Impulsive Behavior Scale in college students. Korean J Clin Psychol 2014; 33: 51-71.

27. Whiteside SP, Lynam DR. The Five Factor Model and impulsivity: using a structural model of personality to understand impulsivity. Pers Individ Dif 2001; 30: 669-89.

28. Choi MR, Jahng S, Kim HS. Emotional instability of depressed individuals: a comparison of variance, autocorrelation and mean square successive difference. Korean J Clin Psychol 2016; 35: 747-57.

29. Hofmann DA, Griffin MA, Gavin MB. The application of hierarchical linear modeling to organizational research. In: Multilevel theory, research, and methods in organizations: 
foundations, extensions, and new directions. Edited by Klein KJ, Kozlowski SWJ.. San Francisco, Jossey-Bass. 2000, pp 467511.

30. Littell RC, Milliken GA, Stroup WW, Wolfinger RD. SAS system for mixed models. Cary, SAS Institute. 1996.

31. Raudenbush SW, Bryk AS. Hierarchical linear models: applications and data analysis methods. 2nd ed. Thousand Oaks, Sage. 2002.

32. McMahon SB, Koltzenburg M, Tracey I, Turk DC. Wall \& Melzack's textbook of pain: expert consult - online. 6th ed. London, Elsevier Health Sciences UK. 2013.

33. Carpenter RW, Trull TJ. Components of emotion dysregulation in borderline personality disorder: a review. Curr Psychiatry Rep 2013; 15: 335.

34. Sebastin SJ. Complex regional pain syndrome. Indian J Plast Surg 2011; 44: 298-307.

35. Riquino MR, Priddy SE, Howard MO, Garland EL. Emotion dysregulation as a transdiagnostic mechanism of opioid misuse and suicidality among chronic pain patients. Borderline Personal Disord Emot Dysregul 2018; 5: 11.

36. Hamilton NA, Zautra AJ, Reich JW. Affect and pain in rheumatoid arthritis: do individual differences in affective regulation and affective intensity predict emotional recovery from pain? Ann Behav Med 2005; 29: 216-24.

37. Mennin DS, Heimberg RG, Turk CL, Fresco DM. Preliminary evidence for an emotion dysregulation model of generalized anxiety disorder. Behav Res Ther 2005; 43: 1281-310.
38. Gross JJ. Emotion regulation: affective, cognitive, and social consequences. Psychophysiology 2002; 39: 281-91.

39. Hwang SH. Construct validation of the Korean Affective Lability Scale-Short Form. Korean J Clin Psychol 2015; 34: 62548.

40. Kosciw JG, Greytak EA, Bartkiewicz MJ, Boesen MJ, Palmer NA. The 2011 National School Climate Survey: the experiences of lesbian, gay, bisexual and transgender youth in our nation's schools. New York, GLSEN. 2012.

41. Bowen R, Baetz M, Hawkes J, Bowen A. Mood variability in anxiety disorders. J Affect Disord 2006; 91: 165-70.

42. Coccaro EF, Harvey PD, Kupsaw-Lawrence E, Herbert JL, Bernstein DP. Development of neuropharmacologically based behavioral assessments of impulsive aggressive behavior. J Neuropsychiatry Clin Neurosci 1991; 3: S44-51.

43. Koenigsberg HW, Harvey PD, Mitropoulou V, New AS, Goodman M, Silverman J, et al. Are the interpersonal and identity disturbances in the borderline personality disorder criteria linked to the traits of affective instability and impulsivity? J Pers Disord 2001; 15: 358-70.

44. Berking M, Schwarz J. Affect regulation training. In: Handbook of emotion regulation. 2nd ed. Edited by Gross JJ. New York, Guilford Publications. 2014, pp 529-47.

45. Speck V, Schlereth T, Birklein F, Maihöfner C. Increased prevalence of posttraumatic stress disorder in CRPS. Eur J Pain 2017; 21: 466-73. 


\section{Appendix. Pain diary}

\section{가. 통증강도}

■ 모든 질문에는 정답이 없으며, 따라서 모든 질문에 한 문항도 빠짐없이 솔직하게 대답해주시고, 귀하께서 생각하시는 답이 없을 경우 최대한 가까운 답에 표기해주시기 바랍니다.

1. 오늘 하루 동안 통증이 평균적으로 어느 정도였습니까?

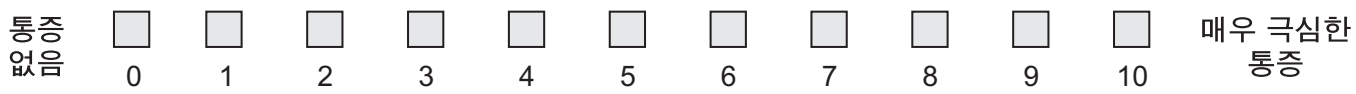

\section{나. 자살사고}

$\square$ 모든 질문에는 정답이 없으며, 따라서 모든 질문에 한 문항도 빠짐없이 솔직하게 대답해주시고, 귀하께서 생각하시는 답이 없을 경우 최대한 가까운 답에 표기해주시기 바랍니다.

2. 오늘 하루 동안 자살에 대한 생각을 얼마나 했습니까?

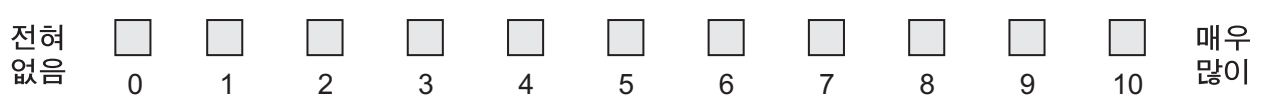

\section{다. 정서}

$\square$ 감정이나 기분을 기술한 아래의 각 단어를 읽고, 오늘 하루 동안 귀하가 느낀 기분의 정도를 가장 잘 나타낸 곳에 표시해주십시오.

\begin{tabular}{|c|c|c|c|c|c|c|}
\hline 번호 & 문항 & 전혀 그렇지 않다 & 약간 그렇다 & 보통이다 & 자주 그렇다 & 매우 그렇다 \\
\hline 1 & 행복한 & (1) & (2) & (3) & (4) & (5) \\
\hline 2 & 즐거운 & (1) & (2) & (3) & (4) & (5) \\
\hline 3 & 기쁜 & (1) & (2) & (3) & (4) & (5) \\
\hline 4 & 만족스러운 & (1) & (2) & (3) & (4) & (5) \\
\hline 5 & 우울한 & (1) & (2) & (3) & (4) & (5) \\
\hline 6 & 슬픈 & (1) & (2) & (3) & (4) & (5) \\
\hline 7 & 화난 / 적대적인 & (1) & (2) & (3) & (4) & (5) \\
\hline 8 & 좌절스러운 & (1) & (2) & (3) & (4) & (5) \\
\hline 9 & 걱정스러운 / 두려운 & (1) & (2) & (3) & (4) & (5) \\
\hline
\end{tabular}

Positive affect (items 1 through 4), negative affect (items 5 through 9). 


\section{라. 충동성}

$\square$ 오늘 하루 동안 행동하고 생각한 방식에 대해 어느 정도 동의하는지를 표시하여 주십시오.

\begin{tabular}{|c|c|c|c|c|c|}
\hline 번호 & 문항 & $\begin{array}{c}\text { 매우 } \\
\text { 동의한다 }\end{array}$ & $\begin{array}{l}\text { 어느정도 } \\
\text { 동의한다 }\end{array}$ & $\begin{array}{l}\text { 동의하지 } \\
\text { 않는다 }\end{array}$ & $\begin{array}{l}\text { 매우 동의하지 } \\
\text { 않는다 }\end{array}$ \\
\hline 1 & 나는 내 충동들을 통제하는데 어려움이 있었다. & (1) & (2) & (3) & (4) \\
\hline 2 & 나는 (음식이나 담배 등에 대한) 욕구를 자제하지 못했다. & (1) & (2) & (3) & (4) \\
\hline 3 & 나는 나중에 벗어나기를 바라는 일에 개입되었다. & (1) & (2) & (3) & (4) \\
\hline 4 & $\begin{array}{l}\text { 나는 기분이 나빴을 때 기분을 좋게 만들기 위해 나중에 후회할 } \\
\text { 일을 종종 했다. }\end{array}$ & (1) & (2) & (3) & (4) \\
\hline 5 & $\begin{array}{l}\text { 나는 기분이 나빴을 때, 하면 할수록 기분이 더 나빠지는 행동을 } \\
\text { 하면서도 잘 멈추지 못했다. }\end{array}$ & (1) & (2) & (3) & (4) \\
\hline 6 & 나는 기분이 상했을 때 종종 생각없이 행동했다. & (1) & (2) & (3) & (4) \\
\hline 7 & $\begin{array}{l}\text { 나는 거부당했다는 느낌이 들었을 때, 나중에 후회하게 될 말을 } \\
\text { 했다. }\end{array}$ & (1) & (2) & (3) & (4) \\
\hline 8 & 감정에 따라 행동하려는 충동을 억제하기가 힘들었다. & (1) & (2) & (3) & (4) \\
\hline 9 & $\begin{array}{l}\text { 나는 기분이 상했을 때 생각 없이 행동하기 때문에 상황을 더 } \\
\text { 나쁘게 만들었다. }\end{array}$ & (1) & (2) & (3) & (4) \\
\hline 10 & 한창 말다툼을 하다가 나중에 후회할 말을 자주 했다. & (1) & (2) & (3) & (4) \\
\hline 11 & 나는 내 기분을 통제했다. & (1) & (2) & (3) & (4) \\
\hline 12 & 나는 나중에 후회할 일들을 충동적으로 했다. & (1) & (2) & (3) & (4) \\
\hline
\end{tabular}

